\title{
Relationship between Cloud Pattern and Female during the Ming and Qing Dynasties
}

\author{
Wen-Jiao LI ${ }^{1, a}$, Hui TAO ${ }^{2, b, *}$ \\ ${ }^{1}$ Graduate Student, School of Fashion, Wuhan Textile University, Wuhan, China \\ 2Professor, School of Fashion, Wuhan Textile University, Wuhan, China \\ a1124777946@qq.com, b932678733@qq.com
}

Keywords: Cloud Pattern, Female, Culture, Relationship.

\begin{abstract}
Cloud pattern has profound cultural connotation and unique decoration significance, and it is a popular clothing decoration pattern during the Ming and Qing period. This paper analyzes the origin and era characteristics of cloud pattern in Ming and Qing period. And putting shoes and cloud shoulder as the breakthrough points, it excavates relations between cloud pattern and female from the perspectives of sociology and feminism, and cultural connotation of them. In order to provide a new research perspective for Chinese traditional patterns, carry forward the traditional culture, and provide theoretical foundation and reference value for modern design.
\end{abstract}

\section{Introduction}

Cloud pattern is one of the most common pattern in Chinese traditional patterns, and is also a unique expression form of traditional decoration art. Appeared from Shang Dynasty, and kept developing until the Ming and Qing dynasties. Characteristics develop from geometrization and abstraction to the delicate exquisite style. For thousands of years, cloud pattern is always under the favour and pursuit of people, and is widely used in many areas such as clothing, architecture, ceramics and painting. It not only reflect the political change and social change, but also is a vivid expression form about religious beliefs and life wishes, and is a symbol of class status and humanistic environment.

\section{The Origins and Era Characteristics of Cloud Pattern}

About the origins and meanings of the cloud pattern, some people think it originated from the imitation of nature, such as intuitive cloud form, or the rotating ripples and rushing waves, or curling vines and coiled animals; some people hold the view that it originated from the evolution of ancient characters. The explanation about the word of "cloud" in the book An Analytical Dictionary of Characters is: The original form of the word" cloud " is “园”, obviously this is a pictographic character. And others think the cloud pattern originated from human body itself and human labor imitation, such as the swirling fingerprint, or easy job to do circular motion when the wrist or elbow as the center, or the twistcore producing in rubbing the rope, spinning and weaving the textile, and mixing mud.

During the Ming and Qing Dynasties, there cloud patterns of Duoyun pattern, Dieyun pattern and Ruyiyun pattern are popular, just shown in Fig. 1, Fig. 2 and Fig. 3. The cloud head polymerizes and cloud tail spreads, with senses of cohesion and weight. It is exquisite, delicate, realistic and succinct. In the late period, the stationary pattern arrangement was established, and the program was obvious, and the clouds were mostly shaped with arcs. It usually used as auxiliary pattern combined with propitious and high-status animal pattern such as the dragon, phoenix, kylin, crane and the auspicious symbol with connotation. Sometimes it also can be used as dominant pattern for decoration. Local decoration and global decoration are two common forms of layout. There are three different decorative forms---single pattern, continuous square, free, and two expressive modes---two-dimensional and three-dimensional. 


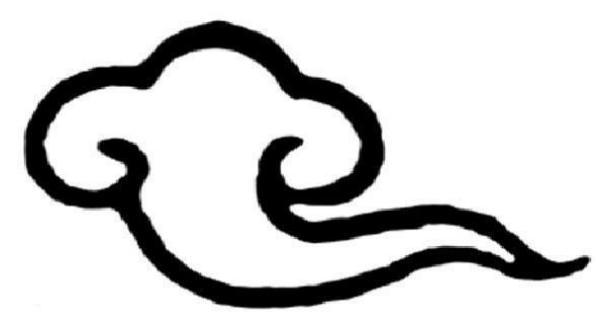

Figure 1. Duoyun pattern

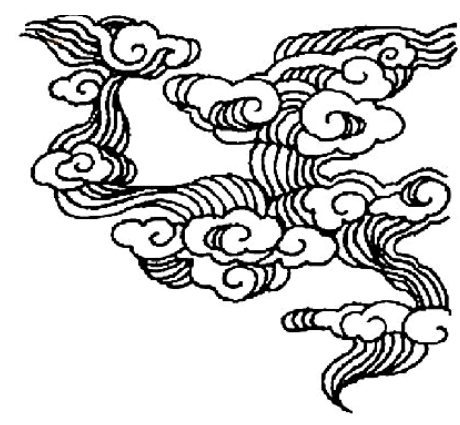

Figure 2. Dieyun patterni
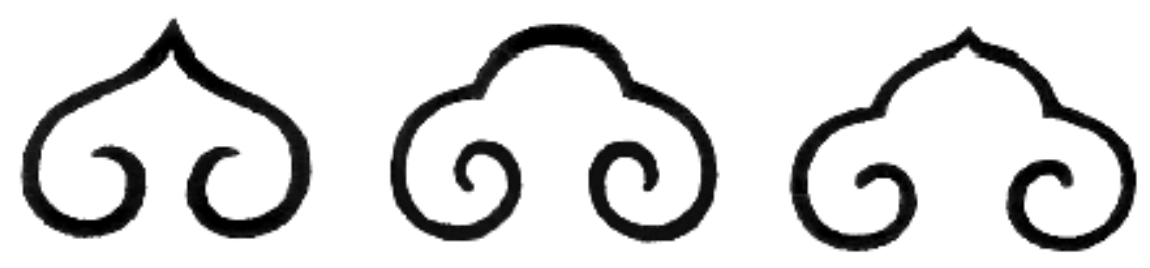

Figure 3. Ruyiyun pattern

\section{Cloud Pattern Embroidery on the Shoes}

Cloud patterns have been widely used in shoes in ancient times. "Three-inch golden lotuses", woman's bound feet in feudal age, is a kind of ancient embroidered shoes, usually with hand embroidery of cloud pattern on surface, just shown in Fig. 4. It is artistic and ornamental, and has very high historical value and cultural value in Chinese. Yuntou shoes is a kind of cloth shoes with two forms--- round toe-cap and square toe-cap. Both Sole and upper are made of cloth. Because the toe-cap is wide, and women can embroider or hollow and carved or inlaid with cloud pattern ornament on the toe-cap, so named. It not only decorates the shoes, but also hook the skirt hemline. The purpose are to avoid tripping and wrestling when walk, at the same time, make the skirt flying along with female graceful postures, so the woman is especially attractive. In ancient times, both men and women can wear Yuntou shoes, and the shapes and colors are all different. In general, women's shoes are more exquisite, more original, and more insightful.

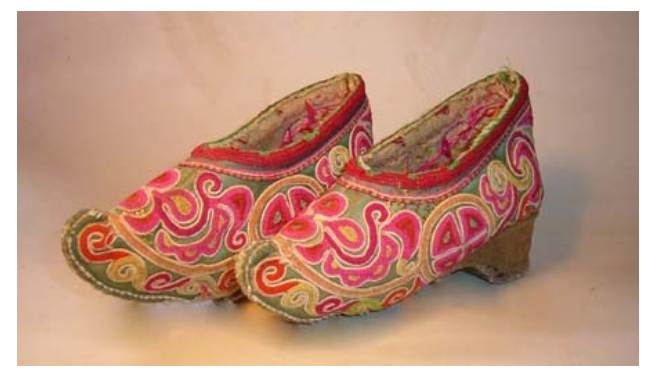

Figure 4. "Three-inch golden lotuses" shoes 
In the seventh chapter of "Jin Ping Mei", Ximen Qing meet Meng Yulou, "Three-inch golden lotuses feet show out under the skirt, beautiful and adorable." After Meng Yulou puts the tea to Ximen Qing, "She gives a polite bow, and Xue Sao goes forward then lift up the woman's skirt, so reveal a part of her little feet, wearing a red silk chopine decorated gold cloud pattern. Ximen Qing is so delighted after looked that. "Yuntou shoes in the Ming and Qing Dynasties are fashionable for a time, become a woman special sexy character in that ages. In the eyes of "tasteful" gentry, at least, it is quite beautiful, and can arouse joy even let a man generate a sexual interest.

In the 29th chapter, Pan Jinlian and Meng Yulou are making shoes together. Yulou is sewing sole, Yulou says, "Why do you do a red flat shoes for nothing? It is not as beautiful as the chopine." Jinlian answers, "The shoes are not for daily activities, just for wearing when sleeping. Our husband tell me to make my sleeping shoes again because it has been stolen and smeared by a servant." Pan Jinlian makes the most popular cloud pattern shoes, in front of other ladies, with her husband's order, is to show Ximen Qing's favourite to her. The display of Pan Jinlian can not only satisfy the vanity to the utmost, but also can confirm and consolidate her position in other women. From that, Yuntou shoes, it is not only a good thing to dress up for their beholders, it is also a silent war between women, especially among men's wives who are favored. So, a pair of fashionable Yuntou shoes can get a glimpse.

Some shoes in China minority often also embroidered with cloud patterns. The Qiang people like to wear Yunyun shoes in some festive days, as shown in Fig. 5. The shape of Yunyun shoes like boats, and the toe cap cocks, and the sole is thicker, uppers are embroidered with colored cloud pattern. The narrative poem "the War of Qiang and Ge" also describes a legend about Yunyun shoes: during the war, an old man with white hair and beard riding a cloud tell the Qiang people a good method to use white stones as weapons, so Qiang people finally overcome Geji. To appreciate the old and commemorate the victory of the war, from then Qiang people worship the white cloud and white stone. The female ancestors get inspiration from clouds, and embroidery it on Yuyun shoes to show their desire---auspicious clouds under feet and turn calamities into blessings. They regard the white clouds as the object of the concept of naturism, to pray for supernatural powers to protect ethnic groups. At the same time, they use this auspicious meaning to express their pursuit of love of nature and the desire for a better life. In general, minority women cannot participate in ethnic affairs, but they win a right to speak because of their embroidered skill. They use needles and threads to record the ethnic history and deeds, and express their ideals and wishes.

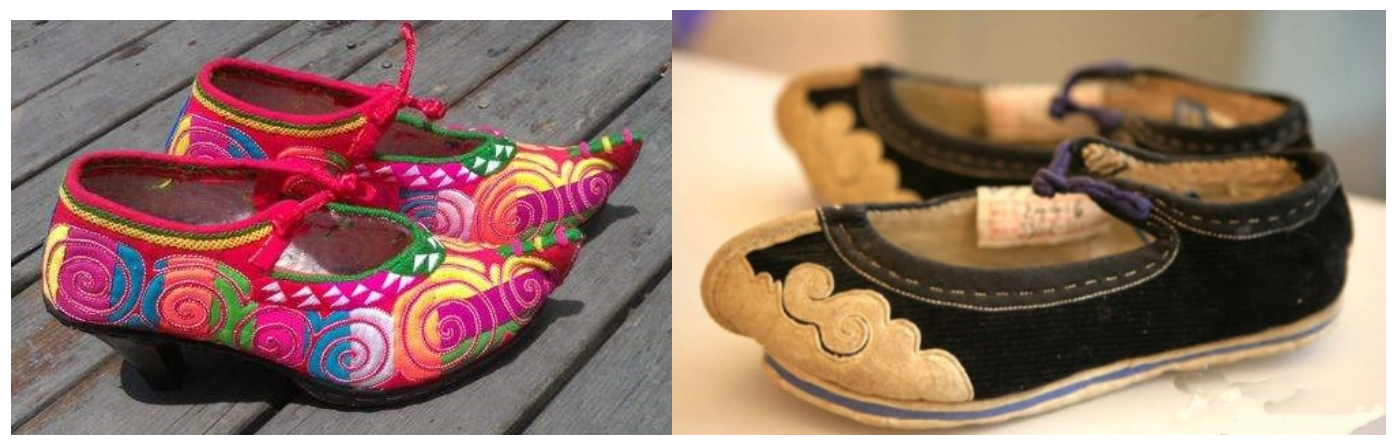

Figure 5. Yunyun shoes in Qiang ethnic minority

\section{Cloud Pattern Embroidery on Cloud Shoulder}

The cloud shoulder, also known as the shawl, is a clothing part that women wear on the shoulders, is an important accessory between the ancient Chinese women, especially in the Ming and Qing Dynasties, as shown in Fig. 6. Initially, it is the simple form from the shawl, in the Ming and Qing Dynasties, it has different styles and various types. It formed a distinctive adornment art features in Chinese women dress. It has become an important landmark and symbol for women clothing at all 
levels in the Han nationality and has a significant position and high research value in the history of the Han nationality folk costume culture.

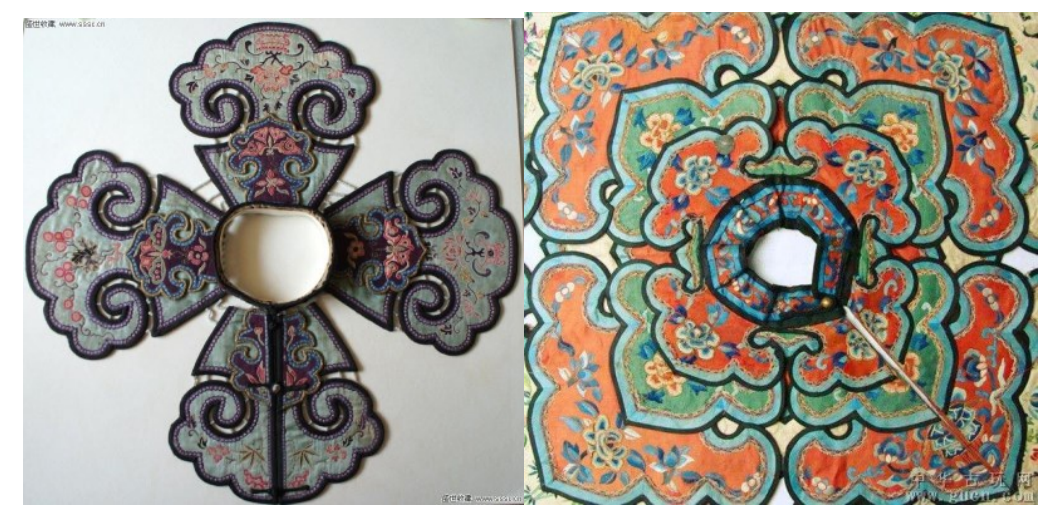

Figure 6. Cloud shoulder

The basic function of the traditional cloud shoulder first is practicability. Li Yu made the shoulder function clear in "Xian Qing Ou Gi": "cloud shoulder protect the collar and keep it clean." In the middle and late Qing Dynasty, its decorative aesthetic significance is far greater than its practical function. "Clear barnyard class notes and clothing" records: "the word cloud shoulder, such as female shoulders that are decorated. Yuan's dancers began to use it, Ming thought that the dress of women's dress. The bride wedding in Han, also for." Especially the higher social status of women taking the shape of cloud shoulder complex structure and three-dimensional sense, exquisite handmade decorative, can be described as folk art treasures, social status and economic status depending on the wearer. To the Qing Dynasty, the cloud shoulder has been very popular, diverse forms and styles, especially when marriage becomes indispensable to young women's clothing.

In late Qing Dynasty, the society is in a pursuit of luxury decoration with complicated atmosphere, follow the top-down also affect the modern consciousness of the folk Yunjian theme selection, especially in the late Qing Dynasty cloud shoulder, can be described as "cloud shoulder will be decorated with ornaments will use paper (pattern), the text will contain auspicious meaning". "Shuowen Jiezi" release "cloud" is a symbol of auspicious. As a kind of art form, the clouds make the coordination between the shoulder and the female body. The name of the cloud by the shoulder, the natural cloud will be more integrated into one of them, so that the whole piece of the shoulder profile of a vivid and harmonious beauty.

In the middle and late Qing Dynasty appeared in six pieces style, eight pieces style or willow style, lotus style and other styles of cloud shoulder, Ruyi cloud texture has been the essence of the formation of the cloud shoulder. If the use of realistic cloud patterns in the cloud is the performance of the people advocating nature, then the cloud as a symbol of the composition of the shoulder of the cloud, its abstract form is people in order to rely on a certain emotion. Wishful meaning auspicious, gratified, almost covered the people's wishes, blessings, ideals of all the good feelings and aspirations. Women through the clouds with wishful cloud shoulder, through the symbolic meaning of the cloud to express the yearning for a better life.

\section{Cultural Connotation of Cloud Pattern}

Cloud pattern is an example of social beauty. Social utility refers to the purpose of human social practice and the requirements to be achieved. The subsistence mode of agriculture is highly dependent on natural conditions, just as the proverb says, "cloud, is foundation of heaven and earth." During the long period of labor practice, the Chinese ancestors attached great importance to the observation of natural phenomena and the understanding of natural law. The ancient ancestors advocate and fear of cloud and rain by praying, witchcraft and other activities. According to Li Zehou (aesthetic) speculated that the cloud pattern is existed as a magic symbol form initially, later people regard cloud 
as a decorative pattern to widely used in construction, pottery, furniture and clothing. Visibly, the use of cloud reflect social utilitarianism for people.

Therefore, the concept of the cloud in the ancient concept of sublimation, abstract, and then interpreted as beyond the natural phenomena and sensory experience of the ideology, so that the natural cloud with sublimation of human significance. The ancestors of the Qi theory, from the people to pray in the process to make the natural gods as changeable as clouds and rain, said the wish. As the cloud is widely decorated in ancient architecture, sculpture, clothing, appliances and all kinds of crafts, cloud meaning from the original "clouds" spirit extended to the auspicious blessings level, the so-called "auspicious clouds". In the Chinese aesthetic world, the cloud is given a subjective will, for example, "auspicious clouds" show some wills, such as good luck, peace, ideal, beautiful and sacred meaning.

In the Ming and Qing Dynasties, the social status of women was lower than that of men. The patriarchal system of family makes women lose their freedom and independence, and become male attachment. Lotus feet is obviously contrary to human relations, and the women's physical and psychological damage is unimaginable. However, temporal women still accept the constraint of aesthetic concept of this era, even embroidered pairs of delicate fancy Yuntou shoes for the malformed feet to cater to the men's appreciation. If we say that female in Ming and Qing Dynasties use Yuntou shoes to pursuit "beauty" from the etic perspective--accept passively social aesthetic standards under the control of male discourse power, then, cloud shoulder, is the creature of temporal female under the active consciousness from the emic perspective. Because what the cloud shoulder bring to woman, is the protection of the physical, is the beauty of decoration, is a wish for a better life.

\section{References}

[1] Wen $\mathrm{Xu}$, Chinese cloud decoration. Guangxi Fine Arts Publishing House, 2000.

[2] Judith Barrett. Gender Trouble: Subversion of feminism and identity [M]. Translated by Song Sufeng. Shanghai Joint Publishing Company, 2009.

[3] R.W. Connell, Gender [M]. Polity Press in association with Blackwell Publishing Ltd, 2002.

[4] Hong-xiu Liu, Ai-min Qi, The cultural connotation and aesthetic value of cloud pattern of shoes. Western leather. 2009.

[5] Huan-jiao Dong, on the aesthetic view of the national costume of the cloud shoulder. Liaoning Silk. 2009.

[6] Hai-mei Shen, Ethnic Identity between Men's "Etic" Versus and Women's "Emic" Orientation: Reflections on Social Gender of Ethnic Identity in Contemporary China. Ethno-National Studies Journal, 2004. 